Dear author,

Please note that changes made in the online proofing system will be added to the article before publication but are not reflected in this PDF.

We also ask that this file not be used for submitting corrections. 


\section{Innovation Cloning: The Introduction and Performance of Private Label Innovation Copycats ${ }^{\text {th }}$}

${ }^{a} \mathrm{KU}$ Leuven, Belgium

${ }^{\mathrm{b}}$ Tilburg University, The Netherlands

\section{Abstract}

A controversial trend in grocery is the practice by retailers to quickly copy innovative national brands (NBs) launched by manufacturers with their own private label (PL). In a sample of 1,100+ NB pioneers launched in The Netherlands between 2005 and 2009, $11.7 \%$ faced a PL copycat by at least one of the seven leading grocery retailers. These copycats obtained an impressive $5.8 \%$ category share at the retailer in the year after launch, thereby outperforming the NB pioneers they copy (2.1\%) as well as non-copycat PLs launched in the same period (4.4\%). Using a two-step selection model, we identify what motivates retailers to copy NB innovations, and what factors drive subsequent copycat performance, thereby taking into account retailers' innovation assortment decisions. As expected, retailers are more likely to copy successful NB innovations, and these copycats indeed perform well in their stores. However, retailers do not only take into account financial considerations. They are especially hesitant to copy heavily promoted NB innovations and those launched by manufacturers with a strong reputation. To enhance copycat performance, retailers should keep prices of the copycat sufficiently below those of the NB pioneer and limit its promotions. Apart from guiding retailers in their copycat decisions, also NB manufacturers can learn from this study how to discourage retailers from imitating their innovations.

(C) 2018 Published by Elsevier Inc. on behalf of New York University.

Keywords: National brand pioneer; Private label copycat; Innovation; Imitation; Retailing

\section{Introduction}

To stay ahead of competition, retailers can offer an innovative assortment that reflects the latest developments in the industry. But developing and introducing a true pioneering innovation that is the first product in a given category to offer novel consumer benefits remains an expensive and risky business. Apart from the $\mathrm{R} \& \mathrm{D}$ and marketing costs involved, pioneers also face a high miss-to-hit ratio: between $35 \%$ and $45 \%$ of products brought to the market fail upon market launch (Cierpicki, Wright, and Sharp 2000). Retailers in particular are further discouraged to engage in own pioneer innovations due to their limited capacity and skills to invest in the broad and diverse set of categories they offer, while the smaller volume generated by private-label (PL)

\footnotetext{
is We would like to thank Marnik Dekimpe for his insightful comments on an earlier draft. We further gratefully acknowledge AiMark for providing access Q1 to the GfK consumer panel and survey data and we thank the Netherlands Organization for Scientific Research (NWO) for financial support.

* Corresponding author at: Naamsestraat 69, 3000, Leuven, Belgium.

E-mail address: anne.terbraak@kuleuven.be (A.ter Braak).
}

offerings (due to retailer exclusivity) and their very competitive prices leave only small margins on PL innovations to recoup the R\&D investments (Steiner 2004). To avoid this, retailers typically wait for national-brand (NB) manufacturers to develop new products and simply decide whether or not to add them to their assortment (Lamey et al. 2018).

But regardless of their adoption decision, retailers may also pursue an imitation strategy and introduce a PL product that contains the innovative feature pioneered by a NB. Kellogg's Special K line of breakfast cereals, for instance, is as famous for its continuous stream of flavor innovations as for its constant battle with retailers copying these new flavors (Culliney 2013). Such an innovation copycat strategy has gained popularity among retailers in the Consumer Packaged Goods (CPG) industry. In this industry, compared to other industries (e.g., the pharmaceutical industry), a low rate of patent and trademark registration is observed by pioneers. Hence, copying innovations (rather than developing them) is an attractive strategy given the lower development costs (because of reverse engineering) and more limited risk of product failure. But unlike manufacturers that copy their rivals' innovations to take part in their success, 
56 retailers are in a unique position and can also use these PLs strate57 gically to influence NB manufacturers and pressure them into ${ }_{58} \quad$ better trade conditions (Steiner 2004). A retailer's role as both 59

a potential distributor of NBs and their innovations, while also offering PL copycats that directly compete with these offerings, makes this case particularly interesting to study.

In the literature, copycats are known as products that resemble visual aspects of mostly leading NBs (e.g., trademark, tradedress, or theme copycats) (Aribarg et al. 2014; Miceli and Pieters 2010; van Horen and Pieters 2012). These studies are primarily concerned with 'trade dress' imitations and the potential harm to -or consumer appreciation of- the imitated brand. However, the present study deals with PL innovation copycats in the Dutch CPG industry. Such copycats are introduced by the retailer to mimic the innovative aspect of a NB pioneer, while visual resemblance is not required per se. ${ }^{1}$ When a NB pioneer introduces novel consumer benefits over existing offerings in the category on one (or more) of its attributes (e.g., new formulation, new ingredient, new usage, new package design/type,...), a PL innovation copycat is defined as a product launched by the retailer that copies this innovative attribute of the NB pioneer introduced earlier on the market.

Even though retailers have a strong incentive to copy innovations, retailers cannot copy -or are not interested in copyingthe abundance of innovations launched on the market each year. Instead, they only selectively copy innovations. Kumar and Steenkamp (2007), for instance, state that retailers most regularly imitate innovations that are 'hits'. However, in many instances, retailers decide to copy different NB innovations, suggesting that also other factors drive their imitation behavior. In this study, we aim to address three main research questions: (i) What factors drive or inhibit retailers to copy a certain NB pioneer? (i.e., identifying retailers' underlying motives to copy); (ii) How do these decisions affect subsequent PL copycat performance at the store, if a copy is introduced?; And (iii) how does a retailer's assortment decision with respect to the innovation pioneer change these relations?

To answer these questions, we collected data for $55 \mathrm{CPG}$ categories on all NB innovation pioneers and their PL copycats introduced in the Netherlands between 2005 and 2009, and use a selection model to simultaneously model the retailer's decision to copy the NB innovation, and the subsequent performance of this PL copycat. Our study can guide retailers in their choice what NB innovations to imitate and how to manage them, while it can reduce retailers' risk of having to withdraw a copycat at a later stage.

\section{Retailer Motivations to Copy Innovations}

Retailers' decision to introduce a PL innovation copycat differs markedly from the launch of an economy, standard, or

\footnotetext{
1 As such, we also differentiate PL innovation copycats from (illegal) counterfeits which impersonate a brand, and design piracy or 'knockoffs', a situation in which a firm creates a copy of another firm's design and appearance without its logo (Appel, Libai, and Muller 2013; Commuri 2009).
}

premium PL tier. The roll-out of these classic PL product lines often encompasses a strategic portfolio decision that involves several categories at the same time (ter Braak, Geyskens, and Dekimpe 2014) while PL copycats target one specific NB in a category. Also, most PLs are introduced as products catering to the price-sensitive segment, but this may be less the case for innovative PL copycats where retailers intend to contribute to a distinct (innovative) category and store-quality image (ter Braak, Geyskens, and Dekimpe 2014). These copycats also do not offer anything unique in the category like premium PLs do. Since a PL copycat will incorporate the innovative feature that is pioneered by a NB, it is directly targeted to compete with the NB innovation it copies, and retailers are advised to position it closely to this NB with the same feature(s) (Choi and Coughlan 2006). While there may still be quality differences between both, there is a close match at the horizontal level, creating a fierce lower-priced competitor for the copied NB pioneer. Thus, manufacturers feel especially threatened by a PL copycat of their NB innovations, yet they remain hesitant to act against retailers on which they depend to distribute their offerings and access the consumer market (Collins-Dodd and Zaichkowski 1999). This dual nature of the retailer-manufacturer relationship will be a key factor driving retailers' imitation decisions that will be taken into account in our analysis.

\section{Research Framework}

Retailers obviously focus to a considerable extent on the expected economic gains of the PL copycat itself, and, as pointed out by industry experts, when developing new PL products, "the decision will hinge on the market potential of the private label product in question" (PlanetRetail 2013, p. 5). But retailers may also introduce innovation copycats (or refrain from doing so) for reasons other than their immediate financial rewards. We advance a research framework that includes both economic and other motives for retailers to introduce (or refrain from introducing) a PL innovation copycat. If considerations other than the direct economic or financial benefits of a PL imitation drive retailers' decisions to launch a PL copycat, the impact on subsequent copycat performance is not straightforward. Hence, we further evaluate the impact of these drivers on copycat performance at the retailer, once introduced. While these factors are expected to directly influence retailers' copycat incentive, their impact may not be independent of the retailer's assortment decision with respect to the original NB pioneer. These relations form the basis of our study and are presented in Fig. 1.

\section{Economic Motives}

The likelihood of introducing a new PL depends on the expected outcome following this decision. Higher expected sales value (through higher volumes, higher prices, or both) increases the likelihood that a retailer will introduce an innovation copycat through their demand pull effect. How well a PL innovation copycat will perform at the store is expected to be directly related 


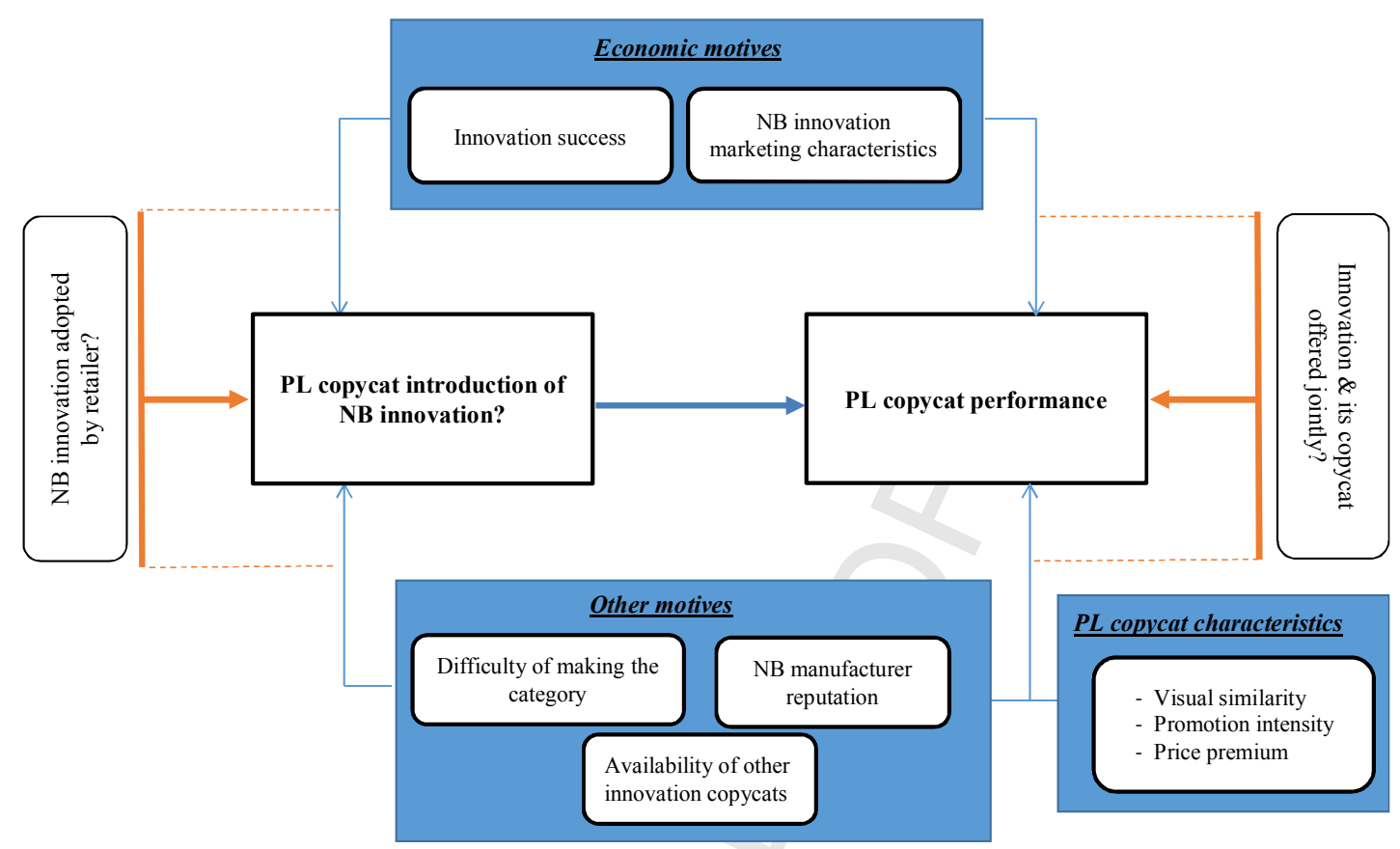

Fig. 1. Research framework.

to (i) the observed performance as well as (ii) the marketing characteristics of the original NB innovation it copies.

\section{Innovation success}

Imitating well-performing NB innovations is an efficient strategy to cope with high levels of uncertainty that market pioneers face (Katz and Shapiro 1985). The observed success of the NB innovation pioneer signals an intrinsic appeal of the innovative feature to consumers, and thus, also a higher expected sales performance for the potential PL variant. The copycat can free-ride on the success of the original NB innovation and may convince especially price-sensitive shoppers to purchase the PL offering instead.

\section{NB innovation marketing characteristics}

Consumers' preference for the NB innovation pioneer over a PL alternative is expected to be influenced by the marketing actions of the copied NB innovation. Four key marketing instruments (i.e., promotions, price, advertising, and innovation activity) have traditionally been used by NB manufacturers in their competition against retailers and their PLs (Lamey et al. 2012). Competing with a NB innovation that offers more frequent and deeper price promotions is tough for a retailer. Their PLs do not have a strong comparative price advantage in that case and the profit margins for a copycat will be more limited (Dhar and Hoch 1997). On the other hand, the larger the NB innovation price premium, the stronger the incentive for consumers to trade down to a PL variant (Kumar and Steenkamp 2007). The expected value of the PL innovation copycat will be higher not only due to its higher potential sales, but also due to the higher copycat price that can still be charged by the retailer (considering the NB innovation's price as the ceiling). Further, heavy $N B$ advertising creates non-price reasons for buying a NB instead of a competing PL (Steenkamp and Geyskens 2014), which would curtail switching from the NB pioneer to a lower-priced PL copycat and limits expected copycat performance. NB advertising is able to stimulate trial purchases and alleviates concerns when consumers are uncertain about the new benefit and quality of an innovation. Finally, frequent $N B$ innovators leave PLs in the unfortunate position of imitating "yesterday's favourite" (Lamey et al. 2012, p. 5). PL copycats positioned closely to the incumbent NB will suffer when a newer NB innovation is launched on the market quickly (Gielens 2012). Alternatively, boosting marketing actions (e.g., more promotions, more advertising) for the NB and its innovation may increase consumers' and retailers' attention to the innovative feature, and consequently, retailers may be more inclined to copy NB innovations with more intense marketing support.

\section{Other Motives}

We consider the factors: (i) the difficulty of making the category, (ii) the reputation of the innovating NB supplier, and (iii) the availability of other NB and PL copycats in the market (see Fig. 1) as more strategic rather than economic motives to introduce a PL innovation copycat (or not). These factors are less concerned with potential copycat demand and the direct financial gains of the $>$ PL copycat itself. Instead, they focus on the ability of a PL innovation copycat to strengthen or weaken the position of a retailer in the market and take into account the sourcing opportunities available to the retailer to produce the copycat.

\section{Difficulty of making the category}

We expect retailers to have a higher incentive to copy pioneers and keep up with the latest innovation trends when it 
217 is more difficult to create high-quality products in the cate${ }_{218}$ gory for several reasons. First, offering a PL innovation copycat 219 in categories that are more difficult to develop could signal 220 that the retailer's brand is at par with the latest developments 221 and quality offered by leading NBs. Thus, PL innovations in 222 such categories are strategically more important to signal the 223 value of the retail brand, which may also transfer to other cate224 gories or even enhance the entire store image (Szymanowski and 225 Gijsbrechts 2012). Also, in categories with larger quality differ226 ences between brands, traditional PLs may be less appealing 227 to consumers, while a PL innovation copycat can reduce con228 sumer risk of purchasing a lower-quality product if it resembles 229 and is closely positioned against the NB pioneer (Steenkamp and 230 Geyskens 2014). Finally, retailers have a bigger incentive to con231 tract with a NB manufacturer instead of a dedicated PL supplier 232 to produce their PLs when it is more difficult to offer high-quality 233 products (ter Braak et al. 2013). These manufacturers offer PLs 234 with the same quality standards as NBs and can easily incorpo235 rate the latest innovative feature into the PL variant, making PL 236 innovation copycats more likely in this setting.
237

\section{NB manufacturer reputation}

The introduction of an innovation copycat may backfire if it upsets a powerful supplier. The power or reputation of a manufacturer is directly related to the strength of its flagship brand(s) (as reflected in the Interbrand top 100 rating; see e.g., Madden, Fehle, and Fournier 2006). Retailers often acquire an important share of their revenues through the brands from powerful manufacturers and they are more dependent on them to source these must-stock items. ${ }^{2}$ Such manufacturers have more resources to retaliate if a retailer upsets them by imitating their innovations, and they are in a better position to punish a retailer by worsening supply agreements or even suspending trade support (Kumar, Scheer, and Steenkamp 1995). This may discourage retailers to copy products from powerful manufacturers even if they expect considerable copycat performance, as it puts their relationship at stake with a supplier they very much rely on. On the supply side, the available resources make high-reputation manufacturers less dependent on strategies such as PL production to earn back their R\&D investment, which would limit the supply opportunities for a retailer's PL copycat.

\section{Availability of other innovation copycats}

Retailers who may be less knowledgeable about the market and lack the time and resources to learn about market preferences across many categories themselves, could have an incentive to simply rely on prevailing practices, and imitate NB innovations with more NB, PL, or both copycats already in the market. So-called "herding" behavior in which retailers imitate NB innovations with more established copycats is an efficient strategy to cope with uncertainty in the market (Katz and Shapiro 1985).

\footnotetext{
2 Manufacturers often offer and manage a portfolio of brands, and may derive their power from only some of these brands. But even if the NB innovation in our sample is not introduced under the most powerful brand name, its manufacturer may still have substantial value to the retailer.
}

More other offerings with the innovative feature also implies that more (NB, PL, or both) sourcing opportunities arise to produce the product efficiently.

\section{The Role of Retailer NB Innovation Adoption}

The incentive to copy NB innovations likely differs for retailers that offer(ed) the original NB innovation within their assortment versus not, although arguments exist in both directions. The adoption of the original NB pioneer could make retailers more inclined to copy since they are better informed about their shoppers' appreciation of the innovative feature and its benefits to the store. Hence, they face a lower risk when adding a PL variant to their assortment (Gielens and Steenkamp 2007). Alternatively, adoption of the NB pioneer could make the PL innovation redundant, as the original NB is able to satisfy these consumer needs. Hence, the retailer may be less inclined to add a close PL substitute in order to prevent assortment overlap (van Herpen and Pieters 2002). On the relational side, retailers with a dual role as both a customer and competitor may introduce a copycat as a means to grow their influence on the NB manufacturer and pressure them into better sourcing conditions related to e.g., wholesale prices or trade support (Groznik and Heese 2010), or they may be discouraged to copy out of fear it will put their established channel relations at stake (Van der Maelen, Breugelmans, and Cleeren 2017). In contrast, when retailers do not offer the NB pioneer, they are less dependent on the innovating NB manufacturers, and hence, negative relational consequences will not prevent them from copying those NB innovations.

Moreover, the extent to which the economic and other motives influence the retailers' copycat introduction decision is expected to be moderated by a retailer's decision to adopt the original NB innovation.

\section{PL Copycat Performance Consequences}

When economic motives drive retailers' imitation decision, PL copycat performance is expected be affected in the same way. In contrast, when it is driven by other considerations like its contribution to a more favorable (innovative) store image, the opportunity to differentiate their outlet from competing retailers, its impact on the retailer-supplier relationship, or both it is not immediately clear if and how they contribute to subsequent copycat performance at the retailer. We leave this as an empirical issue in our study.

But once introduced, also the positioning and marketing actions of the innovation copycat are expected to influence its performance, and thus, are taken into account. A more blatant (visually similar) copycat positioning that closely matches the shape, color, or both of the pioneer is more likely to transfer the positive associations related to the original NB to its copy (Miceli and Pieters 2010). Also, PL copycat performance is expected to increase when copycat promotion intensity is higher, and its price relative to the original NB is lower. Finally, copycat performance likely differs depending on whether the NB pioneer is also available within the assortment or not. Joint presence 
could enhance copycat performance by the so-called attraction effect (Geyskens, Gielens, and Gijsbrechts 2010) or could limit performance due to increased in-store competition for the innovative feature. Again, the extent to which the motives influence copycat performance may be moderated by a retailer's decision to present both offerings jointly on the shelf.

\section{Research Setting and Data}

The empirical setting is the grocery retail market in the Netherlands. All retailers with a (value) market share of $3 \%$ or more in 2009 were considered. Albert Heijn, a retailer by the domestic Ahold Group, has a clear dominant position in the Netherlands with a market share of $32.8 \%$ in 2009 that more than doubles the shares of the next-in-line, C1000 and Aldi, who hold a share of $11.7 \%$ and $8.3 \%$, respectively. We further examine copycat behavior by the retailers Super de Boer (6.5\%), Plus (6.0\%), Lidl (5.4\%) and Jumbo (4.9\%). Together with Spain, the U.K., Germany, and France, the Dutch CPG market is a frontrunner with regards to PL penetration, with an average PL share of 26\% (De Jong 2011).

\section{Sample}

The main data source for this study is household scanner panel data collected by GfK in the Netherlands. The data are available from January 2004 until December 2010 for a sample of 21 broad categories (corresponding to 55 subcategories) which are carried by each retailer included in our study. In these categories, innovations are introduced regularly, and they represent slow-moving as well as fast-moving categories (see Table 1).

First, an independent research assistant identified all innovation pioneers launched by NB manufacturers in the Dutch market in our categories. After that, the assistant scanned for each of the seven retail chains all PL introductions to determine if these new PLs are a copycat of one of the NB innovations identified in the previous step.

\section{Innovation identification}

To identify NB innovation pioneers, all mother brands (e.g., "Gillette" is the mother brand of the subbrand "Gillette Fusion") with a category share across the key retailers over the years 2005-2006 exceeding 1\% were selected. For this set of brands, all newly introduced stockkeeping units (SKUs) were identified between April 2005 and July 2009. A three-month initialization period was used before April 2005 to distinguish new SKU introductions from out-of-stocks. To qualify as an original or 'genuine' NB pioneer, the new SKU should offer novel consumer benefits (e.g., a new formulation, new ingredient, new flavor, new package design/type,...) in the category that are not already available or observed with any other product in that category in earlier years. In line with this definition, SKUs with non-novel attributes were excluded; that is attributes that were already offered by other SKUs in that category. ${ }^{3}$ To that extent, the detailed SKU product descriptions (as provided in the GfK panel data) for all SKUs sold in the category within the timeframe of our data were inspected case-by-case. Also, web searches were conducted for the product names and for the EAN (European Article Number) code to obtain additional product information for each SKU. In line with Gielens (2012), we also discarded pure SKU proliferation when it comes to new package sizes, temporary SKUs, and promotional items. We focus on innovation pioneers at the SKU level (e.g., both "Gillette Fusion Balsam" and "Gillette Fusion Hydra Care" were classified as separate NB innovations) as we observe that retailers do not necessarily copy all varieties of a subbrand. Only NB SKUs with different package sizes of the same innovation are aggregated to represent one entry in our dataset.

This procedure yielded 1,106 NB innovations introduced in the Dutch CPG market across the 55 categories. Since we examine copycat activity by each of the seven main Dutch retailers, this resulted in 7,742 observations $(=1,106 \times 7$ retailers). Our sample includes a wide range of both very successful and unsuccessful NB pioneers, which is further evidenced by the fact that about $30 \%$ of the 1,106 innovations do not even obtain. $10 \%$ national market share (mean NB innovation share in national category sales equals .83\%; see Table 2 ).

\section{PL copycat identification}

PL innovation copycats are all products introduced by a retailer that copy the innovative aspect(s) of a NB pioneer launched earlier in the market (as identified before). To identify such PL innovation copycats, the assortment at each of the seven chains was screened for new PL SKU additions during the same time span (April 2005 and July 2009). To assess whether the innovative feature(s) of the original NB innovation is copied by a PL in the same category, the detailed GfK product descriptions, again complemented with an online search for the EAN, of each new PL SKU were inspected. This similarity assessment was based on several criteria: formulation similarity (e.g., C1000 Tortilla Chips Cool American as a copycat of Doritos Cool American), resemblance in innovative ingredients (e.g., O'Lacy's full taste Thai Sweet Chili-Koriander Chips as a copycat of Lays Sensations Thai Sweet Chili), similarity in concept (e.g., the general idea of emphasizing the richness of the taste of the potato chips), packaging similarity, or both (e.g., the yogurt stand-up pouch "Breaker" introduced by Friesche Vlag, a dominant Dutch dairy brand). Using these criteria, we identified 213 PL innovation copycats (mostly belonging to the standard tier) across 55 categories that copied one of the 1,106 NB innovations introduced in the Dutch market.

\footnotetext{
${ }^{3}$ Data of 2004 is not only used to measure the covariates of PL copycats that enter the market in 2005 , but also to verify that the innovative feature of the identified new offering is not already available in the category by a competing product before 2005. Still, we acknowledge that our dataset is left-censored which means that we cannot certify that the attribute was never offered before 2004 .
} 
Table 1

Q8 Category coverage.

\begin{tabular}{|c|c|c|c|}
\hline Product group & Category examples $(n=55)$ & \# NB innovations & \# PL innovation copycats \\
\hline Beverages & Beer, bottled water, coffee & 57 & 21 \\
\hline Food & Cereal, chips, yogurt & 368 & 73 \\
\hline Household care & Laundry detergent, fabric conditioner & 116 & 26 \\
\hline Personal care & Deodorant, shampoo, toothpaste & 412 & 48 \\
\hline Petfood & Catfood, dogfood & 153 & 45 \\
\hline Total & & 1,106 & 213 \\
\hline
\end{tabular}

These 213 PL copycats correspond to 129 out of the 1,106 identified NB pioneers $(11.7 \%)$. After checking for outliers, our final sample includes 7,733 observations to evaluate a retailer's PL copycat introduction decision, pertaining to 1,105 innovations and 210 PL innovation copycats for which the performance can be assessed. ${ }^{4}$

\section{Measures}

\section{PL copycat performance}

PL copycat performance is measured as the sales of the PL innovation copycat relative to total retailer sales in the category during the first 12 months after its introduction (cf. Lamey et al. 2018). We use value rather than volume shares to take into account that copycat performance could be driven by higher sales volume, higher prices, or both of the copycat. A relative (percentage) measure is also comparable across categories expressed in different measurement units (gram, liters,...). On average, PL copycats obtained a 5.8\% share in the category at the retailer $($ S.D. $=10.5 \%)$.

\section{Drivers of copycat introduction/performance}

The proposed drivers originate from a diverse set of sources, mostly the GfK panel data, but also supplemented with consumer survey data (to evaluate 'difficulty of making the category'), expert judgements ('copycat visual similarity' was coded by an independent research assistant who determined whether the copycat has a similar shape, color, or both - next to copying the innovative aspect, using the available copycat product information), Interbrand data (to measure manufacturer reputation), and Nielsen advertising data.

\section{Control variables}

Finally, we control for other factors that have been found in the literature to stimulate retailers to introduce more PLs in general. In particular, retailers' inclination to proliferate their PL line has been found to be related to the category proliferation, the category value or size, and the PL share in the category at the retailer (ter Braak, Geyskens, and Dekimpe 2014). We further account for other retailer differences by including a hard

\footnotetext{
${ }^{4}$ Seven of the 9 deleted observations from the original set of 7,742 observations correspond to one NB innovation outlier (with one corresponding copycat) and the remaining two to copycat outliers. These outliers are in the category miscellaneous pet food and they are based on extreme innovation or copycat price premium values that are more than 60 times larger than the mean of all remaining observations.
}

discounter dummy (for Aldi and Lidl) and a dummy for market leader Albert Heijn (with other traditional retailers as our baseline), and control for other unobserved differences across categories by including a food dummy (with non-food as the baseline). Finally, we account for the year of NB innovation launch by including year dummies. In the performance model, we include the time (in months) between the introduction of the original NB innovation and its copycat instead of the year dummies, as this can only be evaluated in case a retailer copies.

We grand-mean-center innovation success, the NB innovation marketing characteristics, difficulty of making the category, the number of available NB and PL innovation copycats, category value, and time since innovation launch, and mean-centered copycat promotions and price premium, PL strength and assortment proliferation at the retailer level, to facilitate interpretation (Cohen et al. 2003). In case of a PL copycat, all predictors were operationalized using data from the calendar year prior to its introduction to preclude that the introduction changes these factors, or, in case no retailer copycat is observed, in the year 2009 (see Table 2 for details on the timing). The copycat characteristics as well as copycat performance are measured during the year of the copycat introduction. Details on the operationalization of all variables, together with the data sources and summary statistics, are presented in Table 2.

\section{Model}

Hamilton and Nickerson (2003) revealed that management's decisions on discrete strategies are often endogenous, and depend on, amongst others, their expected performance outcome. Hence, we use a selection model that accounts for the fact that a retailer's decision on whether or not to introduce a copycat and its subsequent performance at the retailer, if introduced, may not be independent. We estimate the following system of Q6 482 equations:

$$
\begin{aligned}
& \operatorname{Pr}\left(P_{L C C_{i b c r}}=1\right)=\Lambda\left[\beta_{0}+\beta_{1} I N N S U C C_{i b c}\right. \\
& +\beta_{2} I N N P R O M_{i b c}+\beta_{3} I N N P R E M_{i b c}+\beta_{4} N B A D V_{b c} \\
& +\beta_{5} N B I N N O V_{b c}+\beta_{6} C A T D I F F_{c}+\beta_{7} R E P U_{b} \\
& +\beta_{8} P_{L C C O T} H_{i b c}+\beta_{9} N B C C O T H_{i b c} \\
& +\beta_{10} I N N A D O P T_{i b c r}+\triangle X+\Phi Z \\
& \left.+\sum_{k=1}^{4} \sigma_{k} \text { COPULAS } S_{i b c}^{k}+u_{i b c r}\right] \text {, }
\end{aligned}
$$


Table 2

Variable operationalization and summary statistics $(n=7,733)$.

\begin{tabular}{|c|c|c|c|c|c|c|c|}
\hline Construct & Operationalization & Data source & Unit & Timing & Mean & Min & Max \\
\hline NB innovation success & $\begin{array}{l}\text { (NB innovation sales volume/national } \\
\text { subcategory sales volume) } \times 100\end{array}$ & Panel data & $\%$ & $\begin{array}{l}12 \text { months before PL } \\
\text { copycat intro or } 2009^{a}\end{array}$ & $.83 \%$ & 0 & $39.4 \%$ \\
\hline
\end{tabular}

characteristics

NB innovation promotion intensity

NB innovation price premium

NB advertising

NB innovation activity

Difficulty of making the category

NB manufacturer reputation

Availability of other innovation copycats Total PL copycats

Total NB copycats

Retailer innovation assortment

NB innovation adoption

Joint assortment presence NB innovation and PL copycat $^{\mathrm{e}}$

PL copycat characteristics Visual similarity

PL copycat promotion intensity
(NB innovation sales volume sold on a price promotion/NB innovation sales volume). A price promotion is identified when the price of the NB innovation is $5 \%$ or more below its median price level within the retailer (cf. Nijs, Srinivasan, and Pauwels 2007)

Ratio of the weighted average national non-promotional NB innovation price to the retailer's weighted average non-promotiona standard PL price (in equivalent units) (cf.

Deleersnyder et al. 2007)

National advertising expenditures for a brand in a subcategory (in thousands of Euros) provided by Nielsen

Total number of innovations that a NB introduced in the subcategory (cf. ter Braak et al. 2013)

Survey measure based on $+/-50$ consumer respondents per category (cf. Steenkamp, van Heerde, and Geyskens 2014):

- In the category XX, making good quality products is difficult $(1=$ strongly disagree, $5=$ strongly agree)

Does the manufacturer own a brand listed on Interbrand Interbrand's list of top 100 brands?

\#PL copycats of the innovation already

Panel data available in the market (acquired through the PL copycat identification procedure) \#NB copycats of the innovation already available in the market (acquired using the same procedure as for the PL copycat identification)

Does the retailer adopt the NB innovation in Panel data its assortment?

Does the retailer offer the NB innovation and Panel data PL copycat jointly in its assortment? $(\mathrm{n}=210)$

Does the PL copycat have a similar package shape, color, or both as the innovation? $(\mathrm{n}=210)$

(PL copycat sales volume sold on a price promotion at the retailer/total PL copycat sales volume at the retailer)

A promotion is identified when the price of the PL copycat is $5 \%$ or more below its median price level within the retailer (cf. Nijs, Srinivasan, and Pauwels 2007) $(n=210)$

Ratio of the retailer's weighted average non-promotional PL copycat price to the weighted average national non-promotional NB innovation price (in equivalent units) (cf. Deleersnyder et al. 2007) $(\mathrm{n}=210)$
Panel data

$\%$

1 year before PL copycat or $2009^{b}$

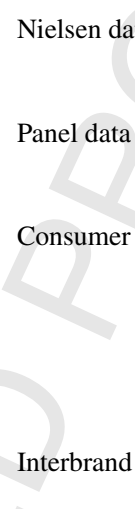

$€$

1 year before PL

$€ 4,204 \quad 0$ copycat or 2009

Count 2005-2009

12

Scale 2003
$0 / 1$

$$
1 \text { year before PL }
$$
copycat or 2009

Count year(s) before PL copycat entry

Count 1 year before PL copycat or 2009

$\begin{array}{lllll}0 / 1 & 2005-2009 & 60 \% & 0 & 1 \\ 0 / 1 \quad \begin{array}{l}\text { year of PL copycat } \\ \text { introduction }\end{array} & 64 \% & 0 & 1 \\ 0 / 1 & 2014 & 38 \% & 0 & 1 \\ \% \quad \begin{array}{l}\text { Year of PL copycat } \\ \text { introduction }\end{array} & .12 & 0 & .56\end{array}$

Panel data introduction
Panel data Ratio
Year of PL copycat introduction

$\begin{array}{lll}.15 & 0 & 5 \\ .18 & 0 & 5\end{array}$
. 
Table 2 (Continued)

\begin{tabular}{|c|c|c|c|c|c|c|c|}
\hline Construct & Operationalization & Data source & Unit & Timing & Mean & Min & $\operatorname{Max}$ \\
\hline \multicolumn{8}{|l|}{ Control variables } \\
\hline Assortment proliferation & $\begin{array}{l}\text { \# unique SKUs offered by the retailer in the } \\
\text { subcategory }\end{array}$ & Panel data & Count & $\begin{array}{l}1 \text { year before PL } \\
\text { copycat or } 2009\end{array}$ & 83 & 0 & 332 \\
\hline Category value & $\begin{array}{l}\text { (Retailer subcategory value sales/total } \\
\text { retailer value sales) } \times 100\end{array}$ & Panel data & $\%$ & $\begin{array}{l}1 \text { year before PL } \\
\text { copycat or } 2009\end{array}$ & $.5 \%$ & 0 & $3.2 \%$ \\
\hline PL strength & $\begin{array}{l}\text { (Retailer PL subcategory sales } \\
\text { volume/retailer subcategory sales volume) }\end{array}$ & Panel data & $\%$ & $\begin{array}{l}1 \text { year before PL } \\
\text { copycat or } 2009\end{array}$ & .46 & 0 & $1^{\mathrm{f}}$ \\
\hline Discounter & $\begin{array}{l}\text { Dummy if retailer is hard discounter Aldi or } \\
\text { Lidl }\end{array}$ & Panel data & $0 / 1$ & n.a. & $29 \%$ & 0 & 1 \\
\hline Albert Heijn & $\begin{array}{l}\text { Dummy if retailer is Albert Heijn (market } \\
\text { leader) }\end{array}$ & Panel data & $0 / 1$ & n.a. & $14 \%$ & 0 & 1 \\
\hline Food & $\begin{array}{l}\text { Dummy to classify food (vs. non-food) } \\
\text { categories }\end{array}$ & Panel data & $0 / 1$ & n.a. & $47 \%$ & 0 & 1 \\
\hline Year 2005 & Dummy if year of innovation launch is 2005 & & $0 / 1$ & n.a. & $35 \%$ & 0 & 1 \\
\hline Year 2006 & Dummy if year of innovation launch is 2006 & & $0 / 1$ & n.a. & $20 \%$ & 0 & 1 \\
\hline Year 2007 & Dummy if year of innovation launch is $2007^{\mathrm{g}}$ & & $0 / 1$ & n.a. & $21 \%$ & 0 & 1 \\
\hline $\begin{array}{l}\text { Time since innovation } \\
\text { launch }^{\mathrm{e}}\end{array}$ & $\begin{array}{l}\text { \# months between NB innovation market } \\
\text { launch and PL copycat launch by the retailer } \\
(\mathrm{n}=210)\end{array}$ & Panel data & Count & n.a. & 31 & 0 & 64 \\
\hline
\end{tabular}

n.a. = not applicable.

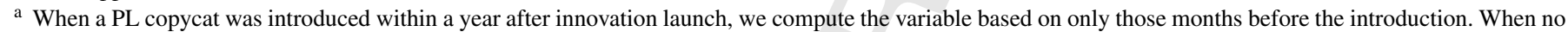
copycat was introduced, we use data from 2009. In case of an innovation delisting, we use data from the most recent 12 months before its delisting.

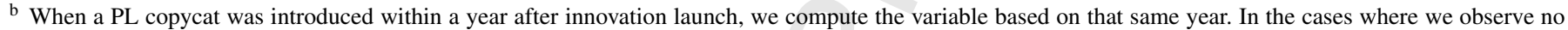

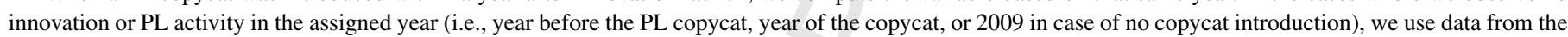
most recent active year.

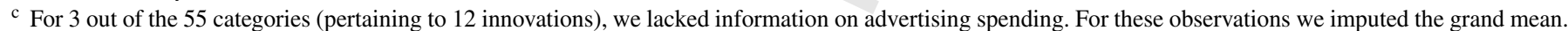

d In case of no PL copycat introduction, we took the total number of copycats in our screening period 2005-2009.

e Variable only available for copied innovations $(n=210)$.

${ }^{\mathrm{f}}$ Discounters have a $100 \%$ PL share in certain categories.

g For innovations launched in 2009, no copycat introduction was observed, which prevented the estimation of a separate parameter for that year. Following Dekimpe et al. (1998), we grouped two consecutive years (i.e., 2008 and 2009) together and use this as the baseline time-period.

$$
\begin{aligned}
& L N\left(\frac{P L C C P E R F_{i b c r}}{1-P L C C P E R F_{i b c r}}\right)=\beta_{0}^{\prime}+\beta^{\prime}{ }_{1} I_{N N S U C C_{i b c}} \\
& +\beta_{2}^{\prime} I N N P R O M_{i b c}+\beta_{3}^{\prime} I N N P R E M_{i b c} \\
& +\beta^{\prime}{ }_{4} N B A D V_{b c}+\beta^{\prime}{ }_{5} N B I N N O V_{b c}+\beta^{\prime}{ }_{6} C A T D I F F_{c} \\
& +\beta^{\prime}{ }_{7} R E P U_{b}+\beta^{\prime}{ }_{8} P L C C O T H_{i b c}+\beta^{\prime}{ }_{9} N B C C O T H_{i b c} \\
& +\beta^{\prime}{ }_{10} I_{N N J O I N T_{i b c r}}+\gamma_{1} \text { PLCCSIM }_{i b c r} \\
& +\gamma_{2} \text { PLCCPROM }_{i b c r}+\gamma_{3} \text { PLCCPREM } i b c r \\
& +\Delta^{\prime} X^{\prime}+\Phi^{\prime} Z^{\prime}+\sum_{k=1}^{6} \sigma_{k}^{\prime} C O P U L A S_{i b c r}^{k} \\
& +\lambda I M R_{i b c r}+u_{i b c r}^{\prime} \text {. }
\end{aligned}
$$

Eq. (1) takes the form of a probit model, where $\operatorname{Pr}\left(\mathrm{PLCC}_{\mathrm{ibcr}}=1\right)$ presents the probability that retailer $r$ introduces a PL copycat of NB innovation $i$ from brand $b$ in category $c$, and the binary variable PLCC takes the value 1 if a copycat is introduced and 0 otherwise. It is linked to the predictors based on the probit link function $\Lambda$, and is estimated on the full sample of all 7,733 observations. It relates the decision by the retailer to introduce a PL copycat (PLCC) to the various drivers: NB innovation success (INNSUCC), the four NB innovation marketing characteristics, namely innovation promotion intensity
(INNPROM), price premium of the NB innovation (INNPREM), NB advertising (NBADV), and NB innovation activity (NBINNOV), the difficulty of making the category (CATDIFF), NB manufacturer reputation (REPU), the other PL (PLCCOTH) and NB copycats (NBCCOTH) of the NB innovation offered in the market, and $\mathrm{NB}$ innovation adoption by the retailer (INNADOPT). The vector $\mathrm{X}$ includes the control variables with $\Delta$ the corresponding vector of coefficients, and the vector $\mathrm{Z}$ contains the relevant interactions with INNADOPT, with $\Phi$ the corresponding vector of coefficients. The INNADOPT variable and its corresponding interactions uniquely feature in the copycat decision equation, but not in the performance equation. These exclusion restrictions, while not absolutely necessary, are useful for identification purposes (Johnston and Dinardo 1997, p. 450). When the unique variables in Eq. (1) are added to Eq. (2), our substantive results remain. Moreover, these variables are insignificant in this model, providing empirical support for their exclusion. Finally, COPULAS refers to the copula-based variables to control for endogeneity in the marketing mix activities (see below).

In Eq. (2), the dependent variable $L N\left(\frac{P L C C P E R F_{i b c r}}{1-P L C C P E R F_{i b c r}}\right)$ captures the performance of the PL innovation copycat from innovation $i$ of brand $b$ in category $c$ at retailer $r$. Since PL copycat performance (PLCCPERF) is quantified in terms of a copycat's category (value) share, it can only take on values in the range between 0 and 1 . To account for this range constraint, we 
use the logistic transformation of the PL copycat's market share as the dependent variable (cf. Ailawadi, Pauwels, and Steenkamp 2008). Eq. (2) is estimated on a subsample of the original dataset with only those 210 observations where the retailer decided to introduce an innovation copycat. We add the same set of predictors to the performance model, and further add the three PL copycat characteristics: copycat visual similarity to the NB pioneer (PLCCSIM), copycat promotion intensity (PLCCPROM), and the price premium of the copycat relative to the NB pioneer (PLCCPREM). When the PL copycat is introduced, we can evaluate whether the NB innovation is jointly present with its copycat on the shelf (INNJOINT) rather than including mere NB innovation adoption by the retailer. Again, a (modified) set of controls is added through the vector $\mathrm{X}^{\prime}, \mathrm{Z}^{\prime}$ contains the relevant interactions with INNJOINT, and COPULAS represents the endogeneity correction terms.

The traditional two-step estimation technique proposed by Heckman (1979) is used, where the inverse mills ratio (IMR), derived from the copycat introduction equation, is added as a predictor in the subsequent copycat performance equation. We further take into account two issues in estimating the model. First, NB manufacturers that introduce an innovation may already take into account potential copycat entry when fixing their marketing actions for the NB innovation, while retailers may also have a priori expectations about PL copycat performance and act accordingly. As a result, the proposed NB innovation and PL copycat characteristics may not be exogenously determined. To account for potential endogeneity concerns, we adopt the instrument-free Gaussian copulas approach of Park and Gupta (2012) and add copula-based control variables linked to the four NB innovation marketing activities in both Eqs. (1) and (2), and two additional copulas terms for the two PL copycat marketing activities ${ }^{5}$ to Eq. (2), operationalized as:

\section{COPULA $S^{k}=\Phi^{-1}\left(H\left(\right.\right.$ variable $\left.\left._{k}\right)\right)$}

where $\Phi^{-1}$ is the inverse of the cumulative normal distribution function, and $\mathrm{H}($.) the empirical distribution of the respective variable $k$. For identification, it is necessary that each variable is non-normally distributed (Park and Gupta 2012). This was confirmed for all four (six) variables in the selection (performance) equation (all $p$ 's <.10). It turns out that, except for advertis-

\footnotetext{
${ }^{5}$ To test for endogeneity of the binary variables visual similarity (yes/no) and joint assortment presence (yes/no) in the copycat performance Eq. (2), we use a 2 SLS regression (cf. Leenheer et al. 2007). As instrumental variables, we use the percentage of visually similar copycats, or the percentage innovations jointly present in the same product group (food, beverages, personal care, or household care) but at other retailers. These instruments pass the Angrist-Pischke test and are sufficiently strong ( $p$-values of the $\mathrm{F}$ test $<.10$ ). The Hausman test shows that we cannot reject the null hypothesis that visual similarity or joint assortment presence is exogenous ( $p$ 's > .10). To test for endogeneity of retailer NB adoption (yes/no) in the copycat introduction Eq. (1), we use a bivariate probit model (cf. ter Braak et al. 2013). We include the percentage of adopted NB innovations in other product groups by the same retailer as a unique variable in the first-stage to identify the model. As $\rho$ (the correlation between the errors of both equations) is insignificant $(p>.10)$ we conclude that NB innovation adoption is exogenous as well.
}

ing, the other three NB innovation marketing characteristics are endogenous to the PL copycat introduction decision $(p<.10)$, and one PL copycat characteristic (copycat price premium) turns out endogenous to PL copycat performance $(p<.10)$.

Second, innovations and their copycats across categories of the same brand can be correlated, which may also be the case for innovations of different brands but within the same category. To account for this, we use robust clustered error-term estimation (cf. Mizik and Jacobson, 2009). Specifically, we adopt the extension to two-way clustering of Cameron, Gelbach, and Miller (2011).

To test whether a retailer's innovation assortment decisions change the impact of the other drivers, we add interactions between the predictors and the NB innovation adoption variable (INNADOPT) to Eq. (1), and with the joint presence variable (INNJOINT) to Eq. (2). Given the limited number of observations in the copycat performance equation $(n=210)$, we build the model by successively adding interactions per block of variables and only retain those that are significant $(p<.20)$ (see van Heerde et al. 2013 for a similar practice). We first augment both equations with the interactions related to the economic drivers. Next, the interactions with the other drivers are added. Finally, interactions with the copycat characteristics are added to the performance Eq. (2).

\section{Results}

\section{Descriptive Insights}

\section{Retailer innovation strategies in the Dutch CPG market}

Table 3 confirms that traditional retailers accept most NB pioneers, whereas only few get access to hard discounters Aldi and Lidl. At the same time, both discounters and traditional retailers engage in innovation imitations. Overall, only a small portion of all NB pioneers in our sample is copied by one of the seven retailers $(11.7 \%$, i.e., $129 / 1,106)$, with market leader Albert Heijn as the biggest 'copycatter' in the Dutch market which copies almost 5\% of all NB pioneers, compared to an average of $2.7 \%$ across all retailers (see Table 3 ). Most innovations ( 82 of 129) were copied by only one of 7 retailers while none of them were copied by all retailers ( $3 \mathrm{NB}$ innovations were copied by a maximum of 5 retailers). Out of the 1,106 pioneers with intrinsic new benefits, $13 \%$ were augmented with extrinsic benefits, while $21 \%$ also provided new usage benefits (classification based on manual coding for the presence of these benefits (yes/no) by an independent research assistant, cf. Gielens 2012). Interestingly, innovations that also provided extrinsic benefits face relatively more copycats compared to those with intrinsic benefits only or a combination with usage benefits.

On average, PL copycats are launched 2.5 years after the NB pioneer entered the market, but $13 \%$ are even launched within the same year. The copycat practice also increased and speeded up over time. In 2006, $227 \mathrm{NB}$ pioneers entered the Dutch market compared to $39 \mathrm{PL}$ copycat introductions that year, resulting in a PL copycat-NB innovation ratio of $17.2 \%$. A comparable ratio of $17 \%$ was observed in 2007 , but in 2008 , it increased to $27.2 \%$, and during the first half of 2009 , this ratio was $42.3 \%$. Moreover, 
Table 3

NB innovation \& PL copycat adoption and timing.

\begin{tabular}{lllll}
\hline & $\begin{array}{l}\text { \# NB innovations } \\
\text { adopted (\%) }\end{array}$ & $\begin{array}{l}\text { \# PL innovation } \\
\text { copycats }\left(\%^{\mathrm{a}}\right)\end{array}$ & $\begin{array}{l}\text { \# copied NB innovations } \\
\text { available at copycat launch? (\%) }\end{array}$ & $\begin{array}{l}\text { Average \# months to } \\
\text { copycat introduction }\end{array}$ \\
\hline Albert Heijn & $986(89 \%)$ & $55(5.0 \%)$ & $49(89 \%)$ & 27 \\
Aldi & $130(12 \%)$ & $20(1.8 \%)$ & $3(15 \%)$ & 28 \\
C1000 & $873(79 \%)$ & $34(3.1 \%)$ & $29(85 \%)$ & 37 \\
Jumbo & $923(83 \%)$ & $25(2.3 \%)$ & $20(80 \%)$ & 32 \\
Lidl & $116(10 \%)$ & $41(3.7 \%)$ & $2(5 \%)$ & 29 \\
Plus & $781(71 \%)$ & $14(1.3 \%)$ & $10(71 \%)$ & 37 \\
Super de Boer & $840(76 \%)$ & $24(2.2 \%)$ & $23(96 \%)$ & 28 \\
Total & 1,106 & 213 & 136 & - \\
Average & $664(60 \%)$ & $30(2.7 \%)$ & $19(63 \%)$ & 31 \\
\hline
\end{tabular}

a Percentage of PL innovation copycats introduced by the retailer to the total number of NB innovations that could potentially be copied $(\mathrm{n}=1,106)$.

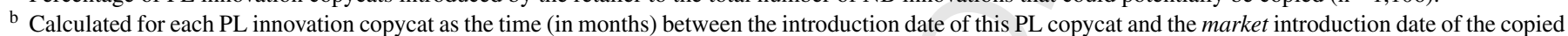
NB pioneer. The reported number is the average across all copycats this retailer offers (see column 3 ).

the average time gap for the first PL copycat to enter the market decreased from 21 months in 2005-2006, to 14 months in 2007, and to just 6 months in 2008. Both the percentage and speed to introduce PL copycats is quite comparable across retailers.

Finally, for a significant part of the PL copycats (25\%), retailers never adopted the original NB pioneer. Here, compared to traditional retailers, hard discounters rarely offer the NB innovation and their PL copycat jointly in their assortment $\left(\chi^{2}(1)=114.70, p<.01\right)$.

\section{Is a PL innovation copycat rewarding for the retailer?}

The mean PL copycat share achieved within the category at the retailer is considerable (see Table 4): its value (volume) share in the first year is $5.8 \%(6.1 \%)$. As a first comparison, the NB pioneers that retailers adopted during our data period perform worse in each of the seven retailers and obtained, on average, only $2.1 \%$ category value share ( $1.7 \%$ in volume) in the first year at the retailer (see Table 4, column 3). Furthermore, the 213 PL copycats outperformed non-copycat PL introductions during our screening period (that were not identified as innovation copycats of the $1,106 \mathrm{NB}$ pioneers; $n=1,635)$. These obtained an average PL value share of $4.4 \%$. Not surprisingly, at the majority of the retailers, copycat performance is slightly worse when compared to retailers' well-established and mature mainstream PLs $(n=727)$ that were permanently available throughout the full period (performance measured in 2005), except at retailers Albert Heijn and Super de Boer where PL innovation copycats still performed better. Against these benchmarks, introducing a PL innovation copycat turns out an interesting alternative to introducing a regular (non-copycat) PL and a rewarding strategy when compared to the adoption of the original NB pioneer, especially when taking into account that retailers obtain higher percentage margins on their PLs than on NBs (Ailawadi and Harlam 2004).

Ideally, PL innovation copycats are able to grow a retailer's category sales. However, no support for this could be found in this study. Retailers' category sales growth does not differ significantly between the pre-launch and launch year, neither in volume (paired $t$-value $=.74, p=.46$ ), nor in value sales (paired $t$-value $=.79 ; p=.43) .{ }^{6}$ Still, we do find that PL category share at the retailer is significantly higher in the year of a copycat entry compared to the year before, in value share (paired $t$-value $=3.41, p<.01)$ and marginally significantly higher in volume share (paired $t$-value $=1.47, p=.14$ ). Combined, these results suggest that a PL innovation copycat is able to steal share from incumbent NBs (among which the NB pioneer, if also present in the assortment), although many other factors may drive these category dynamics at the retailer.

\section{Model Results}

None of the VIF statistics exceeded the recommended cutoff-value of 10 in the copycat introduction model (Cohen et al. 2003), while in the PL performance model only two VIF statistics marginally exceeded this cut-off value, ${ }^{7}$ suggesting that multicollinearity is not a major concern. The estimated selection coefficient $\lambda$ of the inverse Mills ratio turns out negative, but is not significant $(p>.10)$, so no evidence of a selection bias is found. However, we keep the selection correction as Shaver (1998) showed that even in the absence of a significant selection effect, failure to account for it may lead to incorrect and misleading conclusions.

The parameter estimates of the final selection model proposed in Eqs. (1) and (2) are presented in Table 5. The estimates per se do not give a good idea about the substantive impact of the various drivers of retailers' likelihood to copy and PL copycat performance because they are measured on different scales. To get a sense of their substantive impact, we follow Dhar and Hoch (1997) and calculate for each driver in our model to what extent the retailer's probability to copy, the PL, or both copycat share will change (in percentage points) if this variable goes

\footnotetext{
${ }^{6}$ Note that we exclude copycats introduced in $2005(n=56)$ in this analysis, since we cannot evaluate growth in the year prior to copycat launch (category sales 2004/category sales 2003) given our data range (2004-2010).

7 These VIF values of 12.45 and 12.10 belong to the variables Innovation Success and its interaction (Joint Assortment Presence*Innovation Success). If we leave out the interaction term, results are stable and the maximum VIF is 6.12 .
} 
Table 4

Benchmarks of copycat performance. ${ }^{\mathrm{a}}$

\begin{tabular}{|c|c|c|c|c|}
\hline & Copycat performance & NB innovation performance & Non-copycat new PL performance & Permanent PL performance \\
\hline Albert Heijn & $3.8 \%$ & $2.0 \%$ & $2.0 \%$ & $3.7 \%$ \\
\hline Aldi & $14.0 \%$ & $1.2 \%$ & $11.2 \%$ & $30.3 \%$ \\
\hline C1000 & $3.7 \%$ & $2.3 \%$ & $3.0 \%$ & $7.0 \%$ \\
\hline Jumbo & $3.3 \%$ & $2.0 \%$ & $3.0 \%$ & $5.0 \%$ \\
\hline Lidl & $7.4 \%$ & $.6 \%$ & $7.8 \%$ & $23.2 \%$ \\
\hline Plus & $4.0 \%$ & $2.5 \%$ & $3.1 \%$ & $6.6 \%$ \\
\hline Super de Boer & $7.6 \%$ & $2.3 \%$ & $3.5 \%$ & $4.2 \%$ \\
\hline Average & $5.8 \%$ & $2.1 \%$ & $4.4 \%$ & $11.4 \%$ \\
\hline
\end{tabular}

a Average value share that the products obtain in the category at the retailer during the first 12 months after introduction, or in 2005 for the permanent PLs.

from one S.D. below its mean to one S.D. above its mean (see Table 5). For binary variables, we report the effect of the logical variation in the variable (e.g., for a low versus high reputation NB manufacturer). To determine these effects, all other variables are fixed at their mean level (or zero for dummies). To benchmark the percentage points change in retailers' copycat probability, recall that, on average, only $2.7 \%$ of the NB innovations was copied by an individual retailer (Table 3). Likewise, average PL copycat share in the category at the retailer across all copycats is $5.8 \%$ (Table 4 ).

\section{What factors drive or inhibit retailers to copy $N B$ innovations?}

The selection model in Eq. (1) fits the data well. Because of the skewed nature of the dependent variable in the copycat introduction model (with many innovations without a copycat introduction), we follow Stepanova and Thomas (2002), and use a cut-off where the number of copycat introductions predicted agrees with the actual number of copycats observed in the sample. That way, we obtain a hit rate of $97.3 \%$ for the copycat introduction equation, which is better than the proportional chance criterion $\left(94.7 \%=\alpha^{2}+(1-\alpha)^{2}\right.$, with $\alpha=2.7 \%$; Morrison 1969). Given that the event of no copycat introduction is much more likely, we also look at the ability of our model to correctly predict the (less likely) event of a copycat introduction. With a chance percentage $(\alpha)$ of $2.7 \%$, our model correctly classifies $30.95 \%$ of the observations with a copycat introduction.

Our results for Eq. (1) (see Table 5, column 2) support that both economic and other motives underlie retailers' decision to copy NB innovations. Consistent with our expectation, we find that more successful $N B$ innovations are more likely to face a PL copycat $\left(\beta_{1}=.04 ; p<.01\right)$, irrespective of whether the retailer adopted this product or not (insignificant interaction with NB innovation adoption). Substantively, the average probability of facing a copycat at one of the main Dutch retailers is $.46 \%$ points higher for successful NB pioneers compared to unsuccessful ones. Retailers also pay close attention to a $N B$ innovation's promotion intensity and copy those of brands with less frequent promotions $\left(\beta_{2}=-1.86 ; p<.01\right)$. Interestingly, heavy promotions by the NB pioneer turn out the most impactful strategy to discourage retailers from copying, with a reduction in a retailer's probability to copy of $1.65 \%$ points compared to NB pioneers with only few promotions, the highest effect among all our drivers (see Table 5). In contrast, the $N B$ innovation price premium and $N B$ advertising actions are unrelated to retailers' likelihood to copy ( $p$ 's $>.10)$. The effect of $N B$ innovation activity is more complex and depends on a retailer's adoption of the original NB pioneer. For NB pioneers that are never adopted by a retailer, NB innovation activity is unrelated to their probability to copy (insignificant $\beta_{5}$ ). But contrary to our expectation, for innovations by NBs that frequently innovate and that are adopted by the retailer, the probability of being copied raises significantly $\left(\varphi_{1}=.03 ; p<.01\right)$.

Our results further support that also other, more strategic factors drive retailers' copycat decisions. Retailers are more inclined to introduce a copycat in categories where it is more difficult to make the product, but only if they adopted the original NB innovation $\left(\beta_{6}+\varphi_{2}=.21+.67=.88 ; p<.05\right)$. According to Table 5 , for NB pioneers that were adopted by the retailer, the likelihood that a PL innovation copycat will be added is $1.26 \%$ points higher when the category is more difficult to make, while the effect of this driver is negligible (increase of only .23\% points) when the retailer never adopted the pioneer.

As expected, retailers are more hesitant to copy NBs of manufacturers with a better reputation $\left(\beta_{7}=-.22 ; p<.10\right)$, with a probability to copy that is $.57 \%$ points lower for these brands. We further find that retailers value the information contained in rival retailers' actions as the number of other PL copycats $\left(\beta_{8}=.13 ; p<.10\right)$ increases the legitimacy of copycatting. Only when a retailer adopts the original NB innovation, the total number of other $N B$ copycats in the market will foster imitation $\left(\beta_{9}+\varphi_{3}=.07+.14=.21 ; p<.01\right)$. Finally, $N B$ innovation adoption also encourages retailer imitation $\left(\beta_{10}=.27 ; p<.05\right)$, and increases the probability to launch their own PL variant with $.88 \%$ points (see Table 5 ).

As to the control variables, we find that retailers with a more elaborate established PL assortment are less likely to engage in further proliferation by adding a PL innovation copycat $\left(\delta_{1}=-.01 ; p<.01\right)$. In line with standard PL literature (Sethuraman and Gielens 2014), retailers are found to engage in imitation based on the category's value share contribution $\left(\delta_{2}=.44 ; p<.01\right)$, while also the strength of their existing PL in that category matters $\left(\delta_{3}=.41 ; p<.10\right)$. Our results further confirm that hard discounters Aldi and Lidl $\left(\delta_{4}=.47 ; p<.01\right)$ and market leader Albert Heijn $\left(\delta_{5}=.32 ; p<.05\right)$ are more likely to copy than the other non-leading traditional Dutch retailers. 
Table 5

Estimation results.

\begin{tabular}{|c|c|c|c|c|c|c|}
\hline \multirow[t]{2}{*}{ Variable } & \multicolumn{3}{|c|}{ Copycat intro } & \multicolumn{3}{|c|}{ Copycat performance } \\
\hline & Coefficient & Z-value & Impact $\mu \pm 1 \mathrm{SD}^{\mathrm{a}}$ & Coefficient & $t$-Value & Impact $\mu \pm 1 \mathrm{SD}^{\mathrm{b}}$ \\
\hline \multicolumn{7}{|l|}{ Economic drivers } \\
\hline Innovation success $\left(\beta_{1}\right)$ & $.04 * * *$ & 3.21 & $.46 \%$ & $.36 * * *$ & 3.43 & $10.34 \%$ \\
\hline NB innovation promo intensity $\left(\beta_{2}\right)$ & $-1.86 * * *$ & -3.16 & $-1.65 \%$ & -.29 & -.39 & $-.15 \%$ \\
\hline NB innovation price premium $\left(\beta_{3}\right)$ & .01 & .26 & $.14 \%$ & $.12(*)$ & 1.52 & $1.28 \%$ \\
\hline NB advertising $\left(\beta_{4}\right)$ & -.00 & -.31 & $-.14 \%$ & -.00 & -.49 & $-.25 \%$ \\
\hline NB innovation activity $\left(\beta_{5}\right)$ & -.02 & -1.27 & $-.99 \%$ & -.00 & -.32 & $-.14 \%$ \\
\hline \multicolumn{7}{|l|}{ Other drivers } \\
\hline Difficulty of making the category $\left(\beta_{6}\right)$ & .21 & .53 & $.23 \%$ & .74 & 1.05 & $.56 \%$ \\
\hline NB manufacturer reputation $\left(\beta_{7}\right)$ & $-.22 *$ & -1.65 & $-.57 \%$ & -.07 & -.29 & $-.15 \%$ \\
\hline Total PL copycats $\left(\beta_{8}\right)$ & $.13^{*}$ & 1.93 & $.37 \%$ & .03 & .22 & $.11 \%$ \\
\hline Total NB copycats $\left(\beta_{9}\right)$ & .07 & .71 & $.24 \%$ & $.31 * * *$ & 2.90 & $1.19 \%$ \\
\hline \multicolumn{7}{|l|}{ Copycat characteristics } \\
\hline Visual similarity $\left(\gamma_{1}\right)$ & - & - & - & .15 & .69 & $.35 \%$ \\
\hline Copycat promotion intensity $\left(\gamma_{2}\right)$ & - & - & - & $-2.05 * * *$ & -2.73 & $-1.51 \%$ \\
\hline Copycat price premium $\left(\gamma_{3}\right)$ & - & - & - & $-.08 *$ & -1.84 & $-.50 \%$ \\
\hline \multicolumn{7}{|l|}{ Retailer innovation assortment } \\
\hline NB innovation adoption $\left(\beta_{10}\right)$ & $.27 * *$ & 2.50 & $.88 \%$ & - & - & - \\
\hline $\mathrm{x} N B$ innovation activity $\left(\varphi_{1}\right)$ & $.03 * * *$ & 2.87 & $.47 \% \%^{\mathrm{c}}$ & - & - & - \\
\hline $\mathrm{x}$ Difficulty making the category $\left(\varphi_{2}\right)$ & $.67 *$ & 1.66 & $1.26 \%{ }^{\mathrm{c}}$ & - & - & - \\
\hline x Total $N B$ copycats $\left(\varphi_{3}\right)$ & $\mathbf{. 1 4}(*)$ & 1.49 & $.91 \%{ }^{\mathrm{c}}$ & - & - & - \\
\hline Joint assortment presence $\left(\beta^{\prime}{ }_{10}\right)$ & - & - & - & .16 & .48 & $.38 \%$ \\
\hline x Innovation success $\left(\varphi_{4}\right)$ & - & - & - & $-.29 * * *$ & -2.68 & $1.87 \% \mathrm{c}^{\mathrm{c}}$ \\
\hline x Total $N B$ copycats $\left(\varphi_{5}\right)$ & - & - & - &.$- \mathbf{3 3} * *$ & -2.38 & $-.11 \%{ }^{\mathrm{c}}$ \\
\hline $\mathrm{x}$ Copycat promotion intensity $\left(\varphi_{6}\right)$ & - & - & - & $2.95 * * *$ & 2.68 & $.78 \%{ }^{\mathrm{c}}$ \\
\hline \multicolumn{7}{|l|}{ Control variables } \\
\hline Assortment proliferation $\left(\delta_{1}\right)$ & $-.01 * * *$ & -6.42 & - & -.00 & -1.05 & \\
\hline Category value $\left(\delta_{2}\right)$ & $.44 * * *$ & 3.38 & & $-.87 * * *$ & -4.29 & \\
\hline PL strength $\left(\delta_{3}\right)$ & $.41 *$ & 1.65 & . & $1.86 * *$ & 2.42 & \\
\hline Discounter dummy $\left(\delta_{4}\right)$ & $.47 * * *$ & 4.29 & 7 & $1.45 * * *$ & 5.42 & \\
\hline Albert Heijn (market leader) $\left(\delta_{5}\right)$ & $.32 * *$ & 2.39 & & $-.52 *$ & -1.93 & \\
\hline Food dummy $\left(\delta_{6}\right)$ & .16 & 1.40 & & .01 & .04 & \\
\hline Year $2005\left(\delta_{7}\right)$ & $1.54 * * *$ & 5.87 & & - & - & \\
\hline Year $2006\left(\delta_{8}\right)$ & $.79 * *$ & 2.59 & & - & - & \\
\hline Year $2007\left(\delta_{9}\right)$ & $.55(*)$ & 1.54 & & - & - & \\
\hline Time since innovation launch $\left(\delta_{10}\right)$ & - & - & & $-.01 * * *$ & -2.94 & \\
\hline C_NB innovation promo intensity $\left(\sigma_{1}\right)$ & $.27 * * *$ & 5.81 & & - & - & \\
\hline C_NB innovation price premium $\left(\sigma_{2}\right)$ & $.17 *$ & 1.91 & & - & - & \\
\hline C_NB innovation activity $\left(\sigma_{4}\right)$ & $.23^{*}$ & 1.75 & & - & - & \\
\hline C_Copycat price premium $\left(\sigma_{6}\right)$ & - & - & & $-.30 *$ & -1.77 & \\
\hline Inverse Mills Ratio $(\lambda)$ & - & - & & -.03 & -.10 & \\
\hline Intercept $\left(\beta_{0}\right)$ & $-3.48 * * *$ & -10.72 & & $-4.57 * * *$ & -7.33 & \\
\hline (Pseudo) R-Square & $29.28 \%$ & & & $57.92 \%$ & & \\
\hline $\mathrm{N}$ & 7,733 & & & 210 & & \\
\hline
\end{tabular}

$* * * p<.01, * * p<.05, * p<.10,(*) p<.15$ (two-sided). Significant effects are indicated in bold.

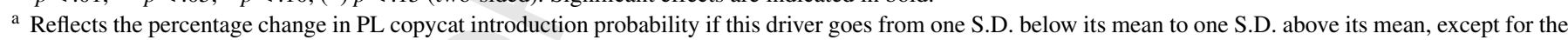
dichotomous variables NB manufacturer reputation and NB innovation adoption that go from 0 to 1 .

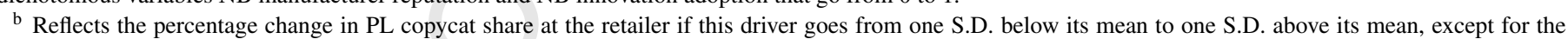
dichotomous variables NB manufacturer reputation, visual similarity, and joint assortment presence that go from 0 to 1 .

c Effect if these drivers go from one S.D. below its mean to one S.D. above its mean with the moderator set to 1.

The year dummies indicate that, as expected, innovations that were launched in earlier years have a higher probability of being copied.

\section{How do these decisions affect subsequent PL copycat} performance?

The $\mathrm{R}^{2}$ of the PL copycat performance model in Eq. (2) is $57.92 \%$. To evaluate if the same factors that drive retailers' imitation decisions also result in better copycat performance, and hence, whether retailers' imitation decisions are justified, we evaluate the results of Eq. (2) in Table 5 (column 3) and compare them to the findings of Eq. (1). First, retailers' practice to copy NB innovations that have become a 'hit' turns out a good strategy. Although the size of this effect differs drastically depending on whether the PL copycat is sold next to the NB pioneer or not $\left(\varphi_{4}=-.29 ; p<.01\right)$, in general, copycats of well performing NB innovations will be more successful themselves $\left(\beta^{\prime}{ }_{1}=.36\right.$; $p<.01 ;$ and $\left.\beta^{\prime}{ }_{1}+\varphi_{4}=.07 ; p<.01\right)$. Its substantive impact is the 
803 highest among all drivers in the copycat performance equation. 804 If both the NB innovation and PL copycat are offered jointly by ${ }_{805}$ a retailer, performance of copycats of successful NB pioneers is $806 \quad 1.87 \%$ points higher than those of less successful ones, but this

increases to more than ten percentage points when the original NB pioneer is absent from the assortment. Clearly, retailers are able to free-ride on the success of the original innovation, but we find that the positive spillover effects are much smaller (i.e., PL copycats benefit far less from pioneer success) in the presence of the original product.

Second, despite retailers' concern about manufacturers' promotions for the NB innovation that were found to deter retailer copycat entry, this factor turns out unrelated to copycat success $(p>.10)$. Retailers should instead focus more on NB innovations that charge a considerable price premium, although the effect is only marginally significant $\left(\beta_{3}^{\prime}=.12 ; p=.13\right)$.

Most of the other, more strategic motivations retailers rely on to copy NB innovations are indeed unrelated to copycat performance. Still, a copycat performs better when more NB copycats exist $\left(\beta^{\prime}{ }_{9}=.31 ; p<.01\right)$. This advantage disappears entirely when the NB pioneer is presented together with the copycat $\left(\varphi_{5}=-.33 ; p<.05\right)$. In this situation, the copycat directly competes with the innovation and perhaps also the other NB copycats, making it more difficult for the copycat to steal market share from the incumbents (in the same store) offering the innovative feature. Further, copycat performance turns out unrelated to the visual resemblance with the original innovation $(p>.10)$. Still, retailers can enhance copycat performance by a proper pricing strategy. Keeping prices of the PL copycat sufficiently below those of the NB pioneer will improve performance $\left(\gamma_{3}=-.08 ; p<.10\right)$. More importantly, price promotions for the PL innovation copycat actually hurt performance $\left(\gamma_{2}=-2.05 ; p<.01\right)$, except when offered next to the NB pioneer $\left(\gamma_{2}+\varphi_{6}=-2.05+2.95=.90 ; p>.10\right)$. Interestingly, in a comparative setting where both the copycat and innovation are present on the shelf, promotions are not necessarily bad given their opposite impact.

Finally, only few control variables have a different effect compared to the copycat introduction model. One notable exception is the effect of category value. While retailers are more likely to introduce copycats in higher value categories, these copycats actually perform worse compared to copycats in lower value categories $\left(\delta_{2}^{\prime}=-.87 ; p<.01\right)$. Further, retailers should not refrain from copying innovations in more proliferated categories as we do not find a lower performance here $(p>.10)$. Note that the most active imitator among the traditional retailers in the Dutch market, Albert Heijn, is less successful than its peers given that the performance of their copycats is significantly lower $\left(\delta^{\prime}{ }_{5}=-.52\right.$; $p<.10)$ than at mainstream retailers. Interestingly, when retailers wait longer before they launch a copycat (i.e., when the time between innovation and copycat launch increases), copycat performance will be lower $\left(\delta_{10}=-.01 ; p<.01\right)$.

We performed several checks to assess the robustness of our results to the estimation method, our sample, and different variants of the copycat performance measure. Results are very stable, as outlined in the Web Appendix.

\section{Discussion}

Retailers in the CPG industry introduce PL innovation copycats that mimic the innovative aspect pioneered by a NB. Although only a small portion of all innovation pioneers (11.7\%) was copied by one of the seven Dutch retailers in our study, these innovation copycats are a growing concern to NB manufacturers. For several NB innovations, we observe that multiple retailers launched a copycat variant and offered it next to, or even instead of, the original product. Moreover, unlike classic PLs, PL innovation copycats are closely positioned against one NB pioneer by offering comparable product features. This way, they compete head on with the pioneer they copy, creating horizontal competition with their NB counterparts (Choi and Coughlan 2006). Accordingly, the drivers of standard (Sethuraman and Gielens 2014), economy (Vroegrijk, Gijsbrechts, and Campo 2016), or premium PL introductions (ter Braak, Geyskens, and Dekimpe 2014) do not readily transfer to PL copycats of NB innovations. Instead, we find that especially the success and marketing characteristics of the NB pioneer as well as relational considerations with the innovating manufacturer (e.g., the dependence on, or reputation of the manufacturer) are taken into account by retailers in their copycat decisions.

\section{Managerial Implications}

We show that retailers can successfully imitate recent NB pioneers and offer the PL variant of this innovation in their assortment with or without the original NB innovation. With an average category share at the retailer of over $5.8 \%$, PL imitations outperform other non-copycat PLs introduced by the retailer while they clearly do better than most of the NB pioneers they copy. But with thousands of new offerings across many categories every year, even large retailers can only selectively introduce PL innovation copycats. Our findings can guide them on what NB innovations to copy, how to manage these copycats, and in what categories they perform best, while they provide retailers with new insights on the performance implications of alternative PL strategies. Next, we summarize several concrete and actionable recommendations for retailers based on our findings:

- Retailers that consider extending their PL product line are recommended to do so with a PL copycat of a successful NB pioneer if their objective is to launch a well performing PL variant. They can take part in the financial gains these products generate;

- Intense pioneer promotions or a strong manufacturer reputation should not discourage retailers from imitating, but they should instead consider copying NB pioneers with a considerable price premium and in categories where their own PL is already strong. Also, NB pioneers that have already been copied by other manufacturers seem to signal high market potential and its PL copycat will perform well;

- Retailers are further encouraged to manage their PL copycats well by limiting the price gap with the original pioneer and refraining from copycat promotions. We also encourage them 
to introduce the PL variant quickly after the NB pioneer has been launched on the market;

- Retailers should tailor their copycat strategies to the innovation assortment composition. First, when retailers copy a moderately successful innovation, they should not be reluctant to add their PL copycat together with the original NB pioneer on the shelf. Second, they should refrain from PL copycat promotions entirely in the absence of the NB pioneer from the assortment, but promotions are justified when the retailer also offers the original NB pioneer.

Nonetheless, retailers may be less driven by the direct financial benefits of a PL copycat and introduce them (or refrain from doing so) for other reasons. In this context, our study has focused on the relational harm and competitive benefits (e.g., reducing their dependence on or enhance their power over the manufacturer, building store traffic, or demonstrating the store's unique image). Still, retailers should realize that with modest copycat performance, other relational or competitive (long-term) benefits are required to justify their imitation decision.

NB manufacturers that are dependent on these large retailers to access the local consumer market may not always take actions against retailer imitations. Indeed, legal cases are still exceptional as "...it is still the case that big brands are very much at the mercy of private label suppliers 'emulating' their innovation" (PlanetRetail 2010, p. 20). As for settling imitation disputes in court on the basis of an intellectual property right infringement, most manufacturers feel uncomfortable suing retailers, as it puts the relationship with one of their main customers at stake (European Commission, 2011). Therefore, also from the perspective of the innovating NB manufacturer, insights on which NB innovations and manufacturers are likely candidates for imitation by retailers would allow them to take the risk of potential copycat entry already into account at the time of innovation launch. More importantly, this allows them to deter copycat entry or limit copycat performance. For them, we formulate the following concrete advice:

- We recommend manufacturers to promote innovative NBs right before or during new product launch as this keeps retailers at bay. Retailers prefer to copy NB innovations that are sold on promotion less frequently, as this leaves ample room for the PL variant to be profitable and to acquire a competitive price advantage;

- Investing in strong brands and building a company reputation though managing leading, high equity brands is a viable longterm strategic objective for innovative firms. Retailers do not want to put their trade relations with powerful manufacturers at stake by imitating their innovations.

- Finally, innovating manufacturers should seriously consider producing PL innovation copycats for retailers (and, in particular, for their more successful pioneers) under the condition that retailer also offers their NB innovation. Even if the PL copycat takes part in the success of their offering, the performance benefits of PL copycats that are offered jointly in a retailer's assortment are much lower, while manufacturers can take part in the considerable volumes these PLs generate to recover some of their R\&D investments.

\section{Limitations and Further Research}

Our findings are based on data from the Netherlands between 2004-2010. We established that the Netherlands closely resembles other major European countries on key retailing statistics, while also being similar to the U.S. on PL activities. At the same time, we realize that the Dutch grocery market is a vibrant environment where PLs develop rapidly and quality perceptions have improved recently. Perceived PL quality has increased dramatically and its share in the Dutch market grew from $21.5 \%$ in 2007 (Nielsen 2011) to $27 \%$ in 2013 (Nielsen 2014). These large PL volumes create more sourcing opportunities for PL innovations. In such markets, retailers are emerging as customer-oriented innovators with relevant and accurate consumer information. PlanetRetail (2017, p. 6) points in this context to the "rise in tailored convenience ranges (e.g., vegetarian convenience) and category innovation", with an increasing number of retailer innovations in ethnic foods, ready-to-eat meals, and organic or fair trade products. This practice and the result of this process remains an unexplored issue, and future research should assess the generalizability of our findings to other developed and emerging countries and extend our analysis to more recent periods.

Second, this study considered several key metrics of copycat performance. However, we did not assess the impact on a retailer's net profit, given the absence of highly confidential margin information across multiple retailers and categories. Since retailers obtain higher margins on PLs than on NBs (Ailawadi and Harlam 2004), further research is needed to provide a conclusive answer to the impact of a PL innovation copycat on retailers' net profits.

Third, we do not consider whether and to what extent the PL copycat harms the original innovation. Along the lines of Pauwels and Srinivasan (2004), one could study who benefits from or is harmed by PL copycat entry. The study by Aribarg et al. (2014) showed that PL 'trade dress' imitation affects consumers' brand consideration and preferences, and thus, harms the imitated NB. However, arguments also exist in the opposite direction. The PL copycat may target a different segment, accelerate adoption due to increased consumer attention to the innovative feature, or create a 'tradeoff contrast' effect (also known as the 'rewarding effect') where consumers' perception of a product can be enhanced by the mere presence of a (less attractive) PL option (Appel, Libai, and Muller 2013). Still, manufacturers remain skeptical and dislike copycats of their brands. As pointed out in industry reports by PlanetRetail (2010, p. 19): "Years of time and billions of dollars ploughed into $R \& D$, marketing, brand equity and NPD can be undermined virtually overnight by copycat private label suppliers". Thus, more research from the perspective of the innovating manufacturer should uncover when and what factors underlie the impact of PL copycats on the original pioneer.

Fourth, future research could analyze the entry timing of PL innovation copycats as opposed to the mere presence of a copycat 
using a (split-) hazard approach. However, theoretically, there are few reasons to expect a different effect for any of our drivers on the likelihood to introduce a PL innovation copycat versus the speed-to-market of this copycat (Sinapuelas and Robinson 2009). Still, a dynamic model may provide insights on the exact order of retailer entry and its impact on copycat performance.

Finally, policy makers (European Commission 2011) have called for more research to study whether PL products reduce choice and hamper innovation in the market. Copycats can be beneficial to consumers in the short term, because they are typically less expensive than their NB counterpart. However, when retailers free-ride on NBs' R\&D efforts, NB manufacturers may not be able to recoup their investments. This behavior could have a vastly negative impact on manufacturers' incentive to invest in $\mathrm{R} \& \mathrm{D}$ and harms long-term consumer welfare. This certainly calls for more research on the societal consequences of retailers' imminent copycat practices.

\section{Appendix A. Supplementary data}

Supplementary data associated with this article can be found, in the online version, at https://doi.org/10.1016/j.jretai. 2018.06.001.

Ailawadi, Kusum and Bari A. Harlam (2004), "An Empirical Analysis of the Determinants of Retail Margins: The Role of Store-Brand Share," Journal of Marketing, 68 (1), 147-65.

Ailawadi, Kusum, Koen Pauwels and Jan-Benedict E.M. Steenkamp (2008), "Private-Label Use and Store Loyalty," Journal of Marketing, 72 (6), 19-30. Appel, Gil, Barak Libai and Eitan Muller (2013), The Short- and Long-Term Impacts of Fashion Knockoffs on Original Items, MSI Report 13-108, Marketing Science Institute.

Aribarg, Anocha, Neeraj Arora, Ty Henderson and Youngju Kim (2014), "Private Label Imitation of a National Brand: Implications for Consumer Choice and Law," Journal of Marketing Research, 51 (6), 657-75.

Cameron, Colin A., Jonah B. Gelbach and Douglas L. Miller (2011), "Robust Inference with Multi-Way Clustering," Journal of Business and Economic Statistics, 29 (2), 238-49.

Choi, Chan S. and Anne T. Coughlan (2006), "Private Label Positioning: Quality Versus Feature Differentiation from the National Brand," Journal of Retailing, 82 (2), 79-93.

Cierpicki, Steven, Malcolm Wright and Byron Sharp (2000), "Managers' Knowledge of Marketing Principles: The Case of New Product Development," Journal of Empirical Generalisations in Marketing Science, 5 (3), 771-90.

Cohen, Jacob, Patricia Cohen, Stephen G. West and Leona S. Aiken (2003), Applied Multiple Regression/Correlation Analysis for the Behavioral Sciences, Mahwah, NJ: Lawrence Erlbaum Associates.

Collins-Dodd, Colleen and Judith Lynne Zaichkowski (1999), "National Brand Response to Brand Imitation: Retailer versus Other Manufacturers," Journal of Product and Brand Management, 8 (2), 96-105.

Commuri, Suraj (2009), "The Impact of Counterfeiting on Genuine-Item Consumers' Brand Relationships," Journal of Marketing, 73 (3), 86-98.

Culliney, Kacey (2013), Kellogg Secretively Reformulates Special K to Outwit Private Label Copycats, Bakery \& Snacks (accessed April 28, 2018), [available at www.bakeryandsnacks.com/Manufacturers/Kelloggsecretively-reformulates-Special-K-to-outwit-private-label-copycats]

De Jong, Koen A.M. (2011), Private Label Uncovered - Taking Retailer Brands to the Next Level, Vught: International Private Label Consult.
Dekimpe, Marnik G., Linda M. Van de Gucht, Dominique M. Hanssens and Keiko I. Powers (1998), "Long-Run Abstinence After Narcotics Abuse: What Are the Odds?," Management Science, 44 (11-1), 1478-92.

Deleersnyder, Barbara, Marnik G. Dekimpe, Jan-Benedict E.M. Steenkamp and Oliver Koll (2007), "Win-Win Strategies at Discount Stores," Journal of Retailing and Consumer Services, 14 (5), 309-18.

Dhar, Sanjay K. and Stephen J. Hoch (1997), "Why Store Brand Penetration Varies by Retailer," Marketing Science, 16 (3), 208-27.

European Commission (2011), The Impact of Private Labels on the Competitiveness of the European Food Supply Chain, Luxembourg: Publications Office of the European Union.

Geyskens, Inge, Katrijn Gielens and Els Gijsbrechts (2010), "Proliferating Private-Label Portfolios: How Introducing Economy and Premium PrivateLabels Influences Brand Choice," Journal of Marketing Research, 47 (5), 791-807.

Gielens, Katrijn (2012), "New Products: The Antidote to Private Label Growth?," Journal of Marketing Research, 49 (3), 408-23.

Gielens, Katrijn and Jan-Benedict E.M. Steenkamp (2007), "Drivers of Consumer Acceptance of New Packaged Goods: An Investigation Across Products and Countries," International Journal of Research in Marketing, 24 (2), 97-111.

Groznik, Ana and Sebastian H. Heese (2010), "Supply Chain Conflict Due to Store Brands: The Value of Wholesale Price Commitment in a Retail Supply Chain," Decision Sciences, 41 (2), 203-30.

Hamilton, Barton H. and Jackson A. Nickerson (2003), "Correcting for Endogeneity in Strategic Management Research,” Strategic Organization, 1 (1), $53-80$.

Heckman, James J. (1979), "Sample Selection Bias as a Specification Error," Econometrica, 47 (1), 153-61.

Johnston, Jack and John Dinardo (1997), Econometric Methods, 4th ed. New York, NY: McGraw Hill Co.

Katz, Michael L. and Carl Shapiro (1985), "Network Externalities, Competition, and Compatibility," American Economic Review, 75 (3), 424-40.

Kumar, Nirmalya, Lisa K. Scheer and Jan-Benedict E.M. Steenkamp (1995), "The Effects of Perceived Interdependence on Dealer Attitudes," Journal of Marketing Research, 32 (3), 348-56.

Kumar, Nirmalya and Jan-Benedict E.M. Steenkamp (2007), Private Label Strategy, Cambridge, MA: Harvard Business School Press.

Lamey, Lien, Barbara Deleersnyder, Jan-Benedict E.M. Steenkamp and Marnik G. Dekimpe (2012), "The Effect of Business Cycle Fluctuations on PrivateLabel Share: What Has Marketing Conduct Got to Do With it?," Journal of Marketing, 76 (1), 1-19.

(2018), "New Product Success in the Consumer Packaged Goods Industry: A Shopper Marketing Approach," International Journal of Research in Marketing, ,. Forthcoming.

Leenheer, Jorna, Harald J. van Heerde, Tammo H.A. Bijmolt and Ale Smidts (2007), "Do Loyalty Programs Really Enhance Behavioral Loyalty? An Empirical Analysis Accounting for Self-Selecting Members," International Journal of Research in Marketing, 24 (1), 31-47.

Madden, Thomas J., Frank Fehle and Susan M. Fournier (2006), "Brands Matter: An Empirical Investigation of Brand-Building Activities and the Creation of Shareholder Value," Journal of the Academy of Marketing Science, 34 (2), 224-35.

Miceli, Gaetano Nino and Rik G.M. Pieters (2010), "Looking More or Less Alike: Determinants of Perceived Visual Similarity between Copycat and Leading Brands," Journal of Business Research, 63 (11), 1121-228.

Mizik, Nathalie and Robert Jacobson (2009), "Valuing Branded Businesses," Journal of Marketing, 73 (6), 137-53.

Morrison, Donald G. (1969), "On the Interpretation of Discriminant Analysis," Journal of Marketing Research, 6 (2), 156-63.

Nielsen (2011), The Rise of the Value-Conscious Shopper. A Nielsen Global Private Label Report, March 2011, The Nielsen Company.

Nielsen (2014), The State of Private Label Around the World. Where It's Growing, Where It's Not, and What the Future Holds, November 2014. The Nielsen Company.

Nijs, Vincent R., Shuba Srinivasan and Koen Pauwels (2007), "Retail-Price Drivers and Retailer Profits," Marketing Science, 24 (4), 473-87. 
Park, Sungho and Sachin Gupta (2012), "Handling Endogenous Regressors by Joint Estimation Using Copulas," Marketing Science, 31 (4), 567-86. Pauwels, Koen and Shuba Srinivasan (2004), "Who Benefits from Store Brand Entry?," Marketing Science, 23 (3), 364-90.

PlanetRetail (2010), Power Shift in FMCG, London: Planet Retail. (2013), Approaching Innovation - The State of Private Label and New Product Development, London: Planet Retail. London: Planet Retail.

Sethuraman, Raj and Katrijn Gielens (2014), "Determinants of Store Brand Share," Journal of Retailing, 90 (2), 141-53.

Shaver, Myles J. (1998), "Accounting for Endogeneity When Assessing Strategy Performance: Does Entry Mode Choice Affect DFI Survival?," Management Science, 44 (4), 571-85.

Sinapuelas, Ian Clark and William T. Robinson (2009), "Entry for Supermarket Feature Me-Too Brands: An Empirical Explanation of Incidence and Timing," Marketing Letters, 20 (2), 183-96.

Steenkamp, Jan-Benedict E.M. and Inge Geyskens (2014), "Manufacturer and Retailer Strategies to Impact Store Brand Share: Global Integration, Local Adaptation, and Worldwide Learning," Marketing Science, 33 (1), 6-26.

Steenkamp, Jan-Benedict E.M., Harald J. van Heerde and Inge Geyskens (2014), "What Makes Consumers Willing to Pay a Price Premium for National Brands over Private Labels?," Journal of Marketing Research, 47 (6), 1011-2.

Steiner, Robert L. (2004), "The Nature and Benefits of National Brand/Private Label Competition,” Review of Industrial Organization, 24 (2), 105-27.

Stepanova, Maria and Lyn Thomas (2002), "Survival Analysis Methods for Personal Loan Data," Operations Research, 50 (2), 277-89.
Szymanowski, Maciej and Els Gijsbrechts (2012), "Consumption-Based CrossBrand Learning: Are Private Labels Really Private?," Journal of Marketing Research, 49 (2), 231-46.

ter Braak, Anne, Barbara Deleersnyder, Marnik G. Dekimpe and Inge Geyskens (2013), "Does Private-Label Production by National-Brand Manufacturers Create Discounter Goodwill?," International Journal of Research in Marketing, 30 (4), 343-57.

ter Braak, Anne, Inge Geyskens and Marnik G. Dekimpe (2014), "Taking Private Labels Upmarket: Empirical Generalizations on Category Drivers of Premium Private Label Introductions," Journal of Retailing, 90 (2), 125-40.

Van der Maelen, Sara, Els Breugelmans and Kathleen Cleeren (2017), "The Clash of the Titans: On Retailer and Manufacturer Vulnerability in Conflict Delistings," Journal of Marketing, 81 (1), 118-35.

van Heerde, Harald J., Maarten J. Gijsenberg, Marnik G. Dekimpe and JanBenedict E.M. Steenkamp (2013), "Price and Advertising Effectiveness over the Business Cycle," Journal of Marketing Research, 50 (2), 177-93.

van Herpen, Erica and Rik G.M. Pieters (2002), "The Variety of an Assortment: An Extension to the Attribute-Based Approach," Marketing Science, 21 (3), $331-41$.

van Horen, Femke and Rik G.M. Pieters (2012), "Consumer Evaluation of Copycat Brands: The Effect of Imitation Type,” International Journal of Research in Marketing, 29 (3), 246-55.

Vroegrijk, Mark, Els Gijsbrechts and Katia Campo (2016), "Battling for the Household's Category Buck: Can Economy Private Labels Defend Supermarkets Against the Hard-Discounter Threat?,' Journal of Retailing, 92 (3), 300-18. 


\section{Executive summary}

A controversial trend in grocery is the practice by retailers to quickly copy innovative national-brands launched by manufacturers with their own private-label brands. Kellogg's Special K line of breakfast cereals, for instance, is as famous for its continuous stream of flavor innovations as for its constant battle with retailers copying these new flavors. In a sample of $1,100+$ national-brand pioneers launched in The Netherlands between 2005 and 2009, 11.7\% faced a private-label copycat by at least one of the seven leading grocery retailers. With an average category share at the retailer in their first year of over $5.8 \%$, these private-label imitations outperform the national-brand pioneers they copy $(2.1 \%)$ as well as non-copycat private labels launched by the retailers in the same period $(4.4 \%)$.

But with thousands of new offerings across many categories every year, even large retailers can only selectively introduce private-label innovation copycats. This study provides insights into three issues: (i) What factors drive or inhibit retailers to copy a particular national-brand pioneer? (i.e., identify retailers' underlying motives to copy); (ii) How do these factors affect subsequent private-label copycat performance at the store, if a copy is introduced? (i.e., assess if these motivations are financially justified); And (iii) how do retailers' assortment decisions with respect to the innovation pioneer change these relations?

The answers to these questions will guide retailers in their decisions what national-brand innovations to imitate, how to manage these innovation copycats, and whether it helps or hurts to offer the original innovation together with its copycat variant within their assortment. These insights also allow retailers to reduce the risk of having to withdraw the private-label at a later stage. National-brand manufacturers, in turn, gain insights into which innovations are likely candidates for imitation by retailers and how to prevent retailer imitations of their innovations.

Using a two-step selection model on a sample of 1,105 innovations with 210 copycats, we show that not only economic (financial) but also more strategic considerations underlie retailers' private-label copycat decisions. Successful innovations are more likely to face a copycat, but retailers are especially hesitant to copy heavily promoted brand innovations and those launched by manufacturers with a strong reputation. Interestingly, retailers likely follow the copycat decisions of their retail peers, but those of national-brand manufacturers only when they adopted the original innovation. For a significant part of the private-label copycats $(25 \%)$, however, retailers never adopted the initial national-brand pioneer. The absence of the pioneer from its assortment decreases the likelihood to copy it. But if available, retailers will copy especially frequent innovators and innovations in categories that are more difficult to make.

To keep retailers at bay, we recommend manufacturers to promote their innovations heavily immediately after product launch and to invest in building strong brands that contribute to a more powerful firm reputation. Especially for successful innovations, they should seriously consider producing private-label copycats of their own innovations for the retailer under the condition that their innovation is listed jointly with the copycat on the retailer's shelf.
Consistent with retailers' observed behavior, private-label imitations of successful branded innovations do significantly better than copies of those with a poor market performance. However, not all factors that drive retailers' imitation behavior also influence copycat performance in the same way. To enhance copycat performance, retailers should keep prices of the privatelabel copycat sufficiently below those of the national-brand pioneer and limit copycat promotions, unless both offerings are jointly available within the retailer's assortment. Thus, retailers should tailor copycat strategies to their assortment composition. Finally, we encourage retailers to launch their private-label variant quickly after the national-brand appears on the market to preempt competitors from grabbing its market potential.

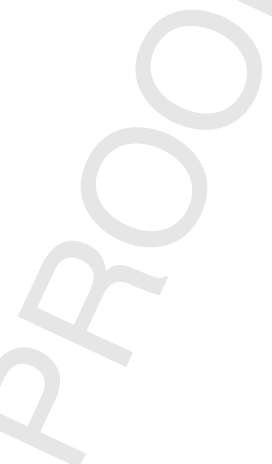

